\title{
Las madres solas en contextos urbanos europeos. Milán y Berlín: puntos en común y divergencias en los procesos de empobrecimiento ${ }^{1}$
}

\author{
Guido Cavalca
}

Università di Milano-Bicocca

Dipartamento di Sociologia e Ricerca Sociale

guido.cavalca@unimib.it

Recibido: 22-04-2008

Aceptado: 07-10-2009

\section{Resumen}

La comparación entre madres solas en una ciudad prospera, Milano (Italia), y una ciudad en crisis económica y laboral, Berlin (Alemania), se dirige a descubrir si existe un modelo único de empobrecimiento urbano, o bien si la construcción social de la pobreza tiene características contextuales. El estudio de las trayectorías biográficas de madres solas ha permitido la construcción de trayectorias ideal-típicas de empobrecimiento. Nuestro trabajo de campo muestra como los procesos de empobrecimiento tienden a divergir entre modelos locales. Entre las madres solas encontramos, por una parte, trayectorias de pobreza recurrente en Milano y, por otra, pobreza prolongada en Berlín.

Palabras clave: empobrecimiento, madres solas, contextos urbanos, análisis dinámico.

Abstract: Lone mothers in European urban contexts. Milan and Berlin: common and diverging elements of impoverishment processes.

The comparison of single mothers in an affluent city, Milan (Italy), and another in economic and employment crisis, Berlin (Germany), aims to verify whether a common pattern of urban impoverishment does exist or poverty has contextual features. The dynamic analysis of biographical trajectories allows for the construction of ideal-typical trajectories of impoverishment. Our fieldwork demonstrates how impoverishment processes tend to diverge between local dynamic models. Among lone mothers we find, on the one hand, recurrent poverty in Milan and, on the other, continuous poverty in Berlin.

Keywords: impoverishment, lone mothers, single mothers, urban contexts, dynamic analysis.

\author{
Sumario \\ 1. Introducción 5. Metodología \\ 2. Referencias teóricas 6. Resultados \\ 3. Hipótesis de investigación 7. Conclusiones \\ 4. El contexto social Referencias bibliográficas
}

1. Agradezco a Luis Garzón la traducción del articulo al español. 


\section{Introducción}

Los estudios sobre la pobreza tienen una larga tradición, lo cual ha dado vida a un vasto patrimonio empírico y teórico. Esto representa una ventaja, pero puede también constituir un límite para las posibilidades de abrir nuevas vías de conocimiento.

La historia de los estudios sociales sobre la pobreza no es lineal. De hecho, a lo largo de su recorrido, se han producido cambios sociales, económicos e ideológicos que han modificado las perspectivas sobre la pobreza y la definición de ésta, lo cual ha cambiado la aproximación subjetiva a dicho recorrido por parte del investigador, los instrumentos de análisis y el interés por un actor social u otro. En resumen, el campo de estudio de la pobreza deja espacio a nuevas contribuciones teóricas y empíricas.

La ciudad es, sin duda, el contexto más útil y adecuado en el cual se pueden estudiar las desigualdades y la pobreza. Las nuevas formas de empobrecimiento, los nuevos sujetos afectados y los nuevos modos de convertirse en pobre constituyen el objeto de estudio más estimulante e innovador en esta fase. La elección, por tanto, de dedicarme a las madres solteras en dos ciudades europeas, Milán (Italia) y Berlín (Alemania), deriva justamente de este razonamiento.

Las mujeres y las familias "en femenino" ${ }^{2}$ asumen, en las ciudades de los países occidentales, una creciente autonomía en las decisiones de vida y de trabajo, lo cual, sin embargo, propicia que se encuentren en mayor riesgo de pobreza. El estudio de las trayectorias de empobrecimiento permite, entre otras cosas, superar el paradigma teórico de la «feminización» de la pobreza, entendida como una mayor frecuencia de ésta en mujeres, para pasar a la comprensión de los mecanismos sociales (incluso los extraeconómicos) y de las dinámicas «típicas» de la pobreza femenina.

La comparación entre contextos urbanos diferentes, una ciudad próspera pero «excluyente» - Milán - y otra en crisis económica y laboral pero «incluyente» - Berlín-, intenta descubrir si existe un modelo unitario de pobreza urbana. ¿Las condiciones estructurales y los macrofenómenos económicos y sociales comunes a las grandes ciudades europeas determinan los modos en los que los sujetos caen en la pobreza, o bien son determinantes el contexto local y su desigualdad específica en la distribución de recursos y constricciones?

En este artículo, se presenta una parte de la investigación realizada entre 2004 y 2006 como parte de la tesis doctoral del autor ${ }^{3}$. En la primera parte, se describirán las bases teóricas de las que ha partido, con particular atención al debate sobre la relación entre género y pobreza. También se afrontarán las definiciones del fenómeno y de sus dimensiones, así como la aproximación meto-

2. Núcleos familiares en los que la persona de referencia es mujer.

3. La tesis se titula Rischi di povertà e processi di impoverimento: $i$ casi di Milano e Berlino y ha sido presentada en el Departamento de Sociología e Investigación Social de la Universidad de Milán Bicocca. La tesis incluía, además, otros colectivos, como los inmigrantes, los parados de larga duración (en Berlín) y las familias con hijos (en Milán). 
dológica utilizada para el estudio de los procesos de empobrecimiento. Sigue un amplio espacio dedicado a los resultados empíricos de la investigación, donde se subrayan las indicaciones generales que este trabajo puede sugerir respecto a la construcción social de la pobreza entre las madres solas.

\section{Referencias teóricas}

El concepto de pobreza tiene una historia tan larga como la sociología. De los primeros estudios surgidos a raíz de la revolución industrial (Engels, 1845; Rowntree, 2000) hasta los análisis sobre la "nueva pobreza» a partir de la transición postindustrial, pasando por la confianza ciega que había durante el periodo "fordista» en la capacidad del capitalismo de eliminar la pobreza, las ciencias sociales han constatado que incluso las sociedades más ricas conservan grandes disparidades económicas y sociales y la pobreza es una «dimensión necesaria e ingrata de las sociedades industrializadas» (Benassi, 2002), un producto «normal» de la reproducción social y no un «mal» funcionamiento de ésta. Esta aproximación es coherente con una de las primeras teorías elaboradas, que ve al pobre como parte integrante del conjunto social, aún si continua siendo materialmente distinto al resto de la sociedad (Simmel, 1989), y asume connotaciones de diferencia radical en términos de recursos económicos y de rol social en cuanto a sujeto con exigencias y capacidades distintas.

En la ya clásica definición de Townsend (1979), la pobreza es la ausencia de los recursos que permiten a los actores sociales vivir en condiciones dignas, seguir las "costumbres normales» y desarrollar las «actividades normales», entre las cuales consta aquélla de construir y mantener relaciones con otros individuos, grupos sociales e instituciones. La aproximación multidimensional es una de las más recientes y útiles contribuciones teóricas al estudio de la pobreza, puesto que los aspectos puramente económicos de ésta (Rowntree, 2000) continúan siendo predominantes, pero la exclusividad de esta caracterización ha sido puesta en discusión. El proceso de empobrecimiento, en particular en la fase actual de la historia, tiende a asumir características acumulativas y multidimensionales (Mingione, 1999). Es oportuno, por tanto, incluir otras dimensiones más allá del rédito (algunas extraeconómicas), como las redes relacionales, las condiciones físicas y psicológicas, la dimensión territorial, la estructura familiar y, más en general, el mercado de trabajo, el Estado de bienestar, el nivel educativo y las condiciones de la vivienda.

Además, los recursos económicos han dejado de ser considerados causantes necesarios del empobrecimiento. Es decir, la dimensión económica de la pobreza puede ser generada por problemas de otro tipo, por ejemplo: una enfermedad o un cambio en la situación de la familia. Aún más, es posible encontrar fenómenos de pobreza no reditual, que, sin embargo, tienen efectos lesivos en los mecanismos de integración social.

El cambio económico en las sociedades denominadas postfordistas, particularmente intenso en las grandes ciudades, ha hecho que las ciencias sociales comiencen a hablar sobre la nueva pobreza urbana. La inestabilidad laboral y 
familiar reduce la capacidad de protección contra la pobreza, lo cual aumenta la presión en los estados de bienestar. Así, emerge una "creciente tensión entre pobreza y sistema de ciudadanía» (Mingione, 1999). Con el cambio socioeconómico desde la década de 1970, se crean nuevas formas de pobreza en los países más ricos del planeta, nuevos cleavage (Lawson, 1995) que afectan a diversos sectores de la población: madres solas; jóvenes adultos que entran en el mercado de trabajo; ancianos con trayectorias laborales discontinuas y salarios bajos; inmigrantes que sufren la escasez de rédito, como también la de redes relacionales de apoyo; trabajadores no cualificados, en especial, mujeres empleadas en servicios caracterizados por un alto riesgo de desocupación, bajos salarios y pésimas condiciones de trabajo, y ausencia de protección sindical. El desempleo sigue siendo la causa fundamental de pobreza, pero es cada vez menos cierto que el trabajo proteja contra la pobreza, como muestra el fenómeno de los working poor originado por la persistencia de las desigualdades en el mercado laboral (Lawson, 1995).

En Europa, la pobreza, como otros fenómenos sociales, tiene un mayor nivel de concentración en las ciudades de tamaño medio y grande. La decisión de estudiar la conformación urbana de la pobreza depende no sólo de esto, ni de la atención renovada de la sociología actual al espacio como elemento del proceso de reestructuración de los fenómenos sociales (Giddens, 1990; Bagnasco y Negri, 1994), sino también de aspectos intrínsecos a la «localización» de los fenómenos sociales. Ciertamente, las formas específicas de la pobreza dependen de variables contextuales, pero la dimensión urbana produce fenómenos coherentes, si bien no homogéneos. Es en este sentido que se puede hablar de pobreza urbana, cuando nos referimos a contextos histórico-sociales relativamente similares en Europa occidental afectados por transformaciones urbanas desde el punto de vista productivo, social y físico ${ }^{4}$. En el ámbito local, ocurren (y se pueden observar) diferenciaciones de condiciones estructurales (macrosociales), así como normas, relaciones y comportamientos de los actores sociales (nivel micro). La pobreza, su producción social y los procesos de entrada y salida de la situación de carencia encuentran una explicación más completa y exhaustiva en el nivel local, donde tienen lugar las dinámicas entre agencia y estructura.

La pobreza está producida por la interacción entre las desigualdades sociales y la acción social de los actores, que concretizan los riesgos estructurales. Los estudios sobre la pobreza deben, por tanto, superar el artificial dualismo teórico entre paradigmas de la estructura y de la acción ${ }^{5}$ (Alcock, 2003), como

4. Para algunos estudiosos de la ciudad, las modificaciones que se suceden en las últimas décadas comportan un auténtico cambio de régimen económico (Sassen, 1999) y la conformación de modelos homogéneos de ciudad situados a grandes distancias la una de la otra, las ciudades globales (Sassen, 2001).

5. El primer paradigma sostiene una explicación de la pobreza a través de la colocación de los individuos y las familias en la estructura social y una visión sustancialmente estática de la pobreza; el segundo paradigma se centra en la privación de la acción de los sujetos, capaz, en una estructura social cambiante y fluida, de determinar (en parte) la propia condición de vida: la condición de privación está considerada temporal y cíclica (Alcock, 2003). 
sucede en la teoría del curso de vida (Leisering y Leibfried, 1999; Leisering $2003)^{6}$, que interpreta la sociedad a través de una visión dinámica de los fenómenos sociales, sintetizando el debate entre Beck (2003) y Mayer (1987) sobre las explicaciones de la desigualdad social.

\subsection{Pobreza en femenino}

La relación entre género y pobreza es un tema central en el estudio de las nuevas formas de pobreza. La industrialización y la urbanización propulsaron a las mujeres a ejercer el rol de sostén interno de la familia, lo que las constriñó a renunciar al trabajo retribuido y, por tanto, las convirtió en económicamente dependientes de la familia. En la sociedad postfordista, las mujeres se vuelven más autónomas a través de su creciente participación en el mercado de trabajo, pero se encuentran sometidas a una fuerte tensión derivada de las crecientes (en cantidad y en calidad ${ }^{7}$ ) demandas de atención que el Estado de bienestar raramente satisface. La mujer, por tanto, sufre sobrecarga de obligaciones familiares, que, junto a la inestabilidad de la vida matrimonial y a la presencia en el mercado de trabajo, contribuye a exponerla a un mayor riesgo de pobreza (Mingione, 2001). La pobreza en femenino existía en la sociedad industrial y existe aún en la sociedad postindustrial. La diferencia consiste, más allá del cambio en los factores sociales y las dinámicas biográficas, en la visibilidad del fenómeno. La pobreza de las mujeres está cada vez menos oculta en las familias y es, por tanto, más evidente en la sociedad.

Las transformaciones familiares y en el rol social femenino desdoblado entre el mercado de trabajo y el hogar son unas buenas claves de lectura para comprender la pobreza en la mujer. Ella se encuentra oscilando, cada vez más, entre periodos vividos en pareja y periodos como soltera y, además, como madre sola. La familia se convierte en «experiencia parcial y transitoria» y ya no permanente (Zanatta, 2003). La diversificación de formas familiares es el resultado de procesos de cambio demográfico y cultural que se acentúan aún más en las grandes ciudades (Zanatta, 2003).

La perspectiva de género ha sido criticada en el debate sociológico, ya que parece insuficiente por sí sola para explicar las nuevas pobrezas urbanas. La especial exposición al riesgo de pobreza constatada en este tipo de núcleo familiar es

6. En el enfoque del curso de vida de Leisering (2003), los pobres son concebidos como actores sociales dotados de agencia y no como víctimas pasivas de las condiciones estructurales de la sociedad, que, a causa de eventos y transiciones comunes en el curso de la vida, permanecen en esta condición por un tiempo transitorio (temporalización); la pobreza no se limita a los grupos marginales de la sociedad (democratización); la variedad de trayectorias posibles dentro de la pobreza (modelo contingente en oposición al modelo determinista) delinea trayectorias continuas o discontinuas, estancias breves o prolongadas en la condición de pobreza (biografización).

7. La actividad de cuidado se diversifica y cambia necesariamente de tipo: se dirige a los hijos, que prolongan el periodo escolar, y a los padres, que, al vivir más, encuentran muchos problemas físicos y psicológicos (Esping-Andersen, 1990). 
debida a una multiplicidad de causas y no a la condición femenina en sí. Por tanto, se plantea la necesidad de ir más allá del paradigma de la "feminización» de la pobreza (Daly, 1992), entendida simplemente como creciente exposición numérica de las mujeres al fenómeno, para pasar a la «dimensión de género de la pobreza», una perspectiva de estudio capaz de comprender condiciones de vida y procesos de empobrecimiento específicamente femeninos (Ruspini, 2000). Más allá de la referencia al género, son las dinámicas biográficas las que asumen una importancia heurística decisiva, puesto que individuan los pasajes críticos y las dimensiones extraeconómicas de la pobreza femenina (Mingione, 2000).

Si bien no hay duda de que el género contribuye a la reproducción de las desigualdades sociales junto a la clase y a la generación (Schizzerotto, 2002), sobre las relaciones entre género y pobreza existen resultados empíricos contradictorios. A escala europea, no parece existir diferencia de exposición al riesgo entre hombres y mujeres. La comparación de la difusión de la pobreza entre los países de la UE indica que el riesgo de las familias encabezadas por una mujer no supera al dato masculino en medida significativa (Eurostat, 2004). Otro estudio empírico, sin embargo, muestra que las mujeres están más expuestas al riesgo en los EUA y en Europa, aunque no en todos los países (Casper et al., 1994) ${ }^{8}$. Nuestros análisis en Milán han verificado una relación solo indirecta entre género y riesgo de pobreza?

Nos falta, por tanto, entender si el género influye sobre la pobreza de forma indirecta o combinada con otros factores sociales, en particular en el tipo de estructura familiar, en la monoparentalidad concretamente, y en la presencia de menores en la familia. A la pobreza de la familia, se añade, en la realidad social, la pobreza en la familia, debida a un desigual acceso a los recursos económicos del núcleo y a la posibilidad de utilizarlos para uno mismo y no sólo (como sucede a menudo a las mujeres en las familias tradicionales) para satisfacer las necesidades de otros componentes. El problema, en este caso, es tener instrumentos de investigación dirigidos a conocer la gestión interna de los recursos económicos de la familia para poder individualizar sujetos pobres en familias no pobres, los que habitualmente se mantienen invisibles ${ }^{10}$.

El estudio en clave dinámica nos ayuda a resolver este problema. El género cuenta ${ }^{11}$, pero por sí solo no basta para explicar la pobreza. Para que no sea

8. En Italia y Holanda, no se encuentran diferencias de género; en Suecia, las mujeres están incluso menos expuestas. Esto sucede por motivos totalmente diversos, que están relacionados con la estructura del mercado de trabajo y los sistemas de Welfare. En Italia en particular, esta situación está condicionada a la aún fuerte difusión del matrimonio y de las formas tradicionales de familia que anula la discriminación de género en los procesos de construcción de la pobreza.

9. Ver Benassi (2005) y Cavalca y Zajczyk (2006).

10. Es útil recordar, a este propósito, que la decisión de estudiar la pobreza a escala familiar (y no individual) se basa en la hipótesis de igual distribución interna de los recursos, que sostiene que cada miembro de un núcleo pobre es pobre.

11. Con una paradoja: «[...] si todos los hombres y mujeres estuvieran casados, no habría diferencias de género en la pobreza» (Casper et al., 1994). 
invisible (Ruspini, 2002a), es necesario combinar el género con otros factores demográficos, familiares y sociales, así como estudiar las transformaciones en las biografías familiares.

Las madres solas son una de las formas familiares más afectadas por la pobreza en la sociedad postfordista. En particular, representan una parte relevante de la pobreza femenina y de la pobreza urbana. La condición monoparental no constituye un factor de por sí suficiente para explicar la vulnerabilidad de estas mujeres a los procesos de empobrecimiento, pero los padres y las madres solos corren riesgos de pobreza muy altos en todos los países desarrollados (Daly, 1992). Son decisivas las desventajas económico-sociales asociadas a las desigualdades de género en el acceso a los recursos en el ámbito del mercado de trabajo, de la familia y del Estado de bienestar (Ruspini, 2002a).

\section{Hipótesis de investigación}

Estudiar los procesos de empobrecimiento tiene como finalidad verificar si existen dinámicas comunes en ciudades con características sociales y económicas diferentes que dan forma a un único modelo de empobrecimiento urbano, o bien si la construcción social de la pobreza tiene fundamentalmente características contextuales, ya que prevalecen factores sociales localizados.

Es, además, importante establecer si las trayectorias de empobrecimiento siguen patrones repetidos o bien si se presentan grandes variabilidades que confirmen las teorías de la desestandarización de las biografías individuales y familiares (Beck, 2003; Mayer, 2003).

En primer lugar, se procede al estudio de los eventos que generan periodos de pobreza (beginning events), después, se realiza un análisis de las trayectorias de empobrecimiento con relación a las biografías individuales.

En relación con los factores de empobrecimiento, la hipótesis es que los dos modelos locales de selección de los pobres y de construcción social de la pobreza generan esquemas divergentes. El análisis se detiene en el número y en la concentración temporal de los eventos críticos, que provocan los procesos de empobrecimiento, lo cual altera la disponibilidad de recursos económicos, relacionales, psicofísicos y la capacidad del sujeto de actuar y reaccionar ante las dificultades ${ }^{12}$.

12. Hablamos de efectos compuestos cuando muchos eventos críticos, producidos en un arco de tiempo limitado, producen un empobrecimiento, y de efectos simples cuando, al contrario, un solo evento comporta problemas económicos y sociales (Siza, 2003). El tipo de efecto depende de la disponibilidad de recursos del actor social en caso de necesidad. Algunos son individuales, como las redes de apoyo relacional, otros son, sin embargo, típicamente contextuales, como la facilidad de acceso al mercado de trabajo o a una casa y la disponibilidad de medidas sociales. Contra más recursos sean utilizables, más articulado resulta, por consiguiente, el proceso de empobrecimiento a causa de la función compensatoria de los recursos. Si este vínculo compensatorio no funciona, porque también en las otras esferas el sujeto está privado de recursos suficientes, entonces el actor se encuentra en condición de pobreza. 
En contextos bienestantes, se puede razonablemente suponer qué acontecimientos negativos aislados en las condiciones de vida de la familia y de los individuos no producen procesos de depauperación, y solo la acción combinada de factores causales da lugar a ellos (Negri, 1990). Si bien es previsible que estas dinámicas sean causadas por efectos compuestos en el contexto afluente milanés y por efectos simples en la "depauperada" Berlín, determinando modelos locales de caída en la pobreza, también es posible la hipótesis de que algunos grupos sociales se distingan del modelo local, lo cual indica que las características de un grupo social son más influyentes que los factores contextuales. La hipótesis es que las madres solas, puesto que están expuestas a muchos factores de riesgo (convergencia entre características estructurales y nuevas formas de desigualdad), caen en la pobreza por un solo evento, también en un contexto medianamente rico como Milán, en el cual los sujetos vulnerables ${ }^{13}$ no son capaces de reaccionar a la dificultad activando recursos alternativos como hacen los sujetos más fuertes.

El análisis de los procesos de empobrecimiento se concentrará sobre un conjunto de elementos: el tipo de evento crítico, su secuencia temporal y causal, la duración de los episodios de pobreza, los eventos resolutivos (ending events) hasta el «momento» biográfico del empobrecimiento y los tiempos de los diversos procesos.

Se pretende verificar si existen elementos comunes entre Milán y Berlín, que podrían ser considerados las características fundamentales de las trayectorias de empobrecimiento urbano, más allá de las especificidades del contexto. Se parte de la hipótesis que hay una convergencia entre contextos urbanos debida al deterioro de las condiciones de vida de una parte de la población de las ciudades, la cual está determinada por la inestabilidad de las trayectorias biográficas típica de las sociedades occidentales postindustriales (Beck, 2003; Mayer, 2003). La inestabilidad laboral y familiar, biográfica en conjunto, es observable como concentración de cambios de condición (transiciones ${ }^{14}$ ) en el tiempo. Se valora también la calidad del cambio, que puede ser más o menos crítico según los efectos sobre los recursos a disposición y la libertad de agencia del actor ${ }^{15}$. El frecuente cambio en la estructura familiar, en particular la interrupción de los proyectos de vida, así como la inestabilidad en el trabajo y, como consecuencia, la pérdida de recursos económicos, provocan carencias y pobreza.

La importancia del nivel local, una vez más, no puede ser ignorada. Los modelos biográficos individuales y familiares están generalmente vinculados

13. El término vulnerabilidad es utilizado aquí para indicar la condición débil de los actores sociales que tienen a disposición un solo recurso para sostener las propias condiciones de vida.

14. Casarse y divorciarse representan dos transiciones de estatus familiar; encontrar o perder un lugar de trabajo son transiciones de estatus ocupacional.

15. El mismo evento - el divorcio, por ejemplo- puede tener efectos psicológicos y económicos negativos o positivos (si la relación matrimonial era de por sí gravosa). 
a características culturales ${ }^{16}$ y socioeconómicas del contexto. Es, por tanto, posible hablar de modelos biográficos locales. La «fase biográfica» del empobrecimiento y sus características (los tiempos de éste en particular) dependen también de ellos. Los modelos biográficos y los sistemas de redistribución de los recursos sociales — la familia, el Estado y, en segundo lugar, el mercadodeberían diferenciar los modelos de empobrecimiento de las madres solas, cuando los factores de riesgo (monorreditualidad y presencia de menores) y el modelo de producción del empobrecimiento (efectos simples) son comunes. Se formula la hipótesis, por tanto, de que las trayectorias de empobrecimiento de las madres solas milanesas y de las berlinesas son procesos típicamente locales. Los tiempos de salida de la familia de origen (precoces en Berlín y retardados en Milán), la modalidad de salida (tipo de núcleo formado por la mujer), los tiempos de transición a la vida adulta, la experiencia de la maternidad vivida en pareja o sola, la relación con el mercado de trabajo (inserción y estabilización ocupacional) deberían favorecer procesos cualitativamente distintos entre las madres solas milanesas y las berlinesas. Según esta hipótesis, por tanto, los factores macrosociales de riesgo son comunes, mientras que los procesos microsociales (las combinaciones biográficas a través de las cuales se produce la pobreza), aunque tienen en común la inestabilidad en la experiencia de los sujetos, divergen entre contextos urbanos ${ }^{17}$.

\section{El contexto social}

\subsection{Dos modelos de ciudad}

El caso de Milán constituye un modelo victorioso de ciudad postindustrial, en la cual la transformación económico-productiva ha tenido éxito desde el punto de vista ocupacional, mientras que otras ciudades industrializadas del norte de Italia (Génova y Turín) han experimentado una dramática pérdida de puestos de trabajo en el sector industrial, sin conseguir substituirlo rápidamente por puestos de trabajo en el sector terciario. Berlín representa, en cambio, el modelo de ciudad con problemas que, en parte por los procesos de terciarización, en parte por las peculiares vicisitudes históricas ${ }^{18}$, afronta una

16. Las normas sociales regulan los tiempos y las formas de salida de la familia de origen, de formación de un nuevo núcleo, las elecciones de procreación y de gestión del vínculo entre hijos y trabajo (femenino).

17. El estudio comparativo de mi tesis de doctorado ha tomado en consideración también a las familias inmigrantes. En este caso, la hipótesis de que estos núcleos experimentan procesos de empobrecimiento similares independientemente del contexto urbano específico ha sido confirmada por el análisis, y es, según mi opinión, explicable en base a estrategias de vida y trayectorias biográficas (más en general agencia) relativamente deslocalizadas.

18. Berlín afronta actualmente un proceso de transformación económica y social profunda, agravada respecto a otras ciudades alemanas y europeas por dos factores: el fin del sostenimiento económico federal y la reunificación de la ciudad que siguió al final del régimen comunista de la RDA en 1989-1990 (Häußermann y Kazepov, 1999). 
profunda crisis ocupacional y fuertes desigualdades sociales concentradas en el espacio ${ }^{19}$.

Desde principios de la década de 1990, Berlín se ha encontrado frente a un doble desafío: enfrentarse al sistema de mercado en la parte este de la ciudad y con el sistema de mercado mundial a este y oeste. El resultado es una crisis de adaptación (Dorsch et al., 2000), un verdadero proceso de empobrecimiento de la ciudad (Kapphan, 2002). Las inversiones no han sido capaces de crear empleo, en particular para trabajadores con bajos niveles de calificación (muy concentrados en Berlín en comparación con otras ciudades), los cuales representan, junto a los inmigrantes, las principales víctimas de la pobreza.

Milán se caracteriza por un nivel medio-alto de riqueza y por una difusión no menos apreciable de la pobreza y la exclusión social, que se presenta, sin embargo, sin fenómenos de concentración espacial, ni siquiera, de hecho, de dispersión (Zajczyk, 2005). El mercado de trabajo es extremadamente dinámico, hasta el punto de que se expande rápidamente incluso en periodos de recesión económica en el ámbito nacional y continental, como durante los últimos años. El mayor riesgo, por tanto, no es la falta de empleo, sino la precariedad del puesto de trabajo para ciertas categorías sociales (jóvenes, mujeres con responsabilidades de cuidado e inmigrantes, en particular los no regulares) y la inadecuación de los subsidios en relación con un coste de la vida muy alto.

La pobreza económica relativa es similar en las dos ciudades ${ }^{20}$, pero este dato esconde la diversa cualidad del fenómeno: la condición de pobreza en Berlín está estrechamente vinculada al desempleo de larga duración con limitadas posibilidades de encontrar soluciones, la relativa generosidad del Estado de bienestar alemán limita notablemente la extensión del fenómeno, pero no la gravedad de éste ni la duración tendencialmente mayor respecto a Milán.

El mercado de la vivienda asume características divergentes en las dos ciudades y ello estructura procesos de selección de la población antitéticos. Berlín es una ciudad «inclusiva» respecto a los grupos sociales en condiciones económicas medio-bajas, y Milán, por el contrario, es «selectiva» (Mingione, 2005). En Berlín, se encuentra una oferta elevada de vivienda de alquiler a precios moderados en un mercado de arrendatarios con fuerte tendencia a la privati-

19. La tendencia a la desregulación del mercado inmobiliario con la consiguiente disminución de la oferta de vivienda pública, el crecimiento demográfico limitado a los inmigrantes y la discriminación residencial que estos sufren crean las condiciones no sólo de segregación espacial (ya en acto), sino también la inicial conformación de una auténtica underclass urbana en algunas zonas de Berlín (Häußermann y Kazepov, 1999).

20. En Milán resulta incluso más elevada por lo que se refiere a las familias e idéntica a la berlinesa por lo que se refiere a los individuos (12,9\%). La línea de pobreza económica relativa coincide con la mitad del rédito medio de la población de referencia. Los datos a los que hacemos referencia vienen elaborados a partir de una investigación sobre Berlín (SGSV, 2002) y Milán (Benassi y Mingione, 2004; Benassi, 2005), que utilizan las mismas técnicas de cálculo del techo de pobreza y son, por tanto, plenamente comparables. 
zación $^{21}$ (Häußermann e Kapphan, 2004). Esto permite que familias de bajo nivel socioeconómico permanezcan en la ciudad y encuentren una solución respecto al habitáculo proporcional al nivel de recursos económicos disponibles (Kapphan, 2002). El proceso de gentrification que experimentan algunos barrios puede, en algunos casos, constreñir a las familias de renta baja a cambiar de zona, pero no a dejar la ciudad a favor de las áreas urbanas adyacentes, como sucede en muchas ciudades europeas (París, Londres y también Milán).

Milán está encuadrada en el modelo italiano de política de vivienda, con apenas presencia del sector público (Tosi, 1984). Dicho modelo está orientado a promover la construcción de edificios nuevos y a favorecer la propiedad, junto a políticas de vivienda pública ineficaces para solucionar las necesidades reales de la población, lo cual ha creado la paradoja de que existan a la vez muchas casas y escasez de vivienda disponible (Tosi, 1984). En Milán, el mercado residencial privado $^{22}$, caracterizado por costes altos y en constante crecimiento, y la oferta de vivienda pública, en disminución, empujan una parte de la población a dejar los confines municipales para trasladarse a las zonas urbanizadas de las afueras.

Los sistemas locales de bienestar de ambas ciudades dependen en buena medida de sistemas nacionales, ambos de tipo ocupacional (Esping Andersen, 1990; Ferrera, 2005; Mingione, 1997), que protegen a aquéllos que están insertados en el mercado de trabajo, en particular, el hombre cabeza de familia. Las medidas (nacionales) de apoyo económico en caso de desocupación ${ }^{23}$, de invalidez y de vejez se basan en principios contributivos y están vinculadas estrechamente a los niveles salariales y a las historias contributivas de los trabajadores (Bonny y Bosco, 2004). El principio de subsidiariedad asume significados diversos en los dos contextos, lo cual da origen a dos variantes del modelo conservador: la estatista e institucionalista (Alemania) y la familista (Italia) (Mingione, 1997, Ferrera, 1996). En Italia, la redistribución de los recursos y del apoyo económico se realiza sobre todo a través de canales familiares (el sistema público se reserva competencias residuales), mientras que, en Alemania, es fundamental el rol del Estado y la política social desplegada por el sector público y el privado social. Aquí la intervención del Estado en apoyo de las personas con problemas - directa o a través del asociacionismo- es neta-

21. Los apartamentos habitados por los propietarios constituían tan sólo el 12,5\% en el año 1993 (5,5\% en la parte este de la ciudad) y las casas de propiedad pública están aún hoy muy presentes (además, la mitad de las casas en Berlín este), aunque en vías de privatización (15\% en los años noventa) a causa de la crisis de las finanzas públicas de la ciudad.

22. La propiedad de la vivienda en Milán es muy alta, 60\% (Zajczyk, 2005: 54), pero, como en todas las áreas urbanas, inferior a la media nacional (71\%; elaboración propia sobre datos del censo de 2001).

23. Por lo que respecta a las ayudas por desempleo, los dos sistemas están estructurados de forma parecida (según el principio contributivo), pero con grados de generosidad muy diferentes por lo que respecta a la protección de los sujetos que han perdido el trabajo. Es muy útil, sobre este caso, el modelo de unemployment welfare regimes propuesto por Gallie y Paugam (2000: 3-13), que distingue entre Alemania e Italia poniéndolas, respectivamente, entre los regímenes employment-centred y sub-protective. 
mente superior al caso italiano, en el cual, tradicionalmente, el núcleo familiar asume una gran parte de los deberes de cuidado y de distribución de los recursos. El sistema de bienestar berlinés garantiza algunas intervenciones a favor de las categorías sociales con problemas. Lo hace a través de la actividad de numerosas asociaciones del tercer sector, en apoyo, en particular, de madres solas, menores, inmigrantes e insolventes ${ }^{24}$.

El carácter familístico-conservador del Estado de bienestar —basado en la familia en Italia y en el tercer sector en Alemania- acerca a ambos países en el rol de reproducción, tanto de la división de género en el interior de la familia, como de la división entre incluidos y excluidos en el mercado de trabajo, con lo cual protege al hombre preceptor de rédito (breadwinner) con una carrera laboral estable, conserva la posición de la mujer como trabajadora no retribuida a cargo de la familia y perjudica a los trabajadores inestables.

Los dos sistemas tienen, sin embargo, una dificultad común respecto a la nueva pobreza urbana, las madres solas, lo que se debe al desajuste entre cambios sociales (la estructura demográfica y familiar y el mercado de trabajo) y el desarrollo del sistema de protección social (Ruspini, 2000). La carencia más grave es la breve baja de maternidad para las madres trabajadoras y la oferta de jardines de infancia, que, en el caso alemán, existían, en cambio, en los Länder orientales y garantizaban una participación femenina muy alta en el mercado laboral (Saraceno, 2004).

\subsection{La condición de las madres solas en los dos contextos}

Existe mayor proporción de madres solteras en Milán que en el resto de Italia; representan el 13,1\% de las familias, aquellas con hijos menores sólo el 4,3\%, equivalente a cerca de 15.000 núcleos (censo poblacional Istat 2001, http://dawinci. istat.it/daWinci/jsp/MD/dawinciMD.jsp), pero, en la vivienda social, los monogenitores (hombres incluidos) llegan al 14,1\% (Zajczyk, 2003). En general, las madres solas, tanto en Milán como en el resto de Italia, disfrutan de una buena inserción en el mercado de trabajo y están, por tanto, relativamente protegidas del punto de vista financiero, ya que, a menudo, están ocupadas a tiempo completo. Las mujeres que se deben ocupar también del cuidado de los hijos permanecen, sin embargo, confinadas en condiciones laborales desfavorables en términos de prestigio y de retribución (Ruspini, 2000), pero disponen del apoyo de las redes familiares, que representa una precondición a la presencia en el mercado de trabajo y un apoyo material y psicológico en las fases de vida más críticas.

La tasa de madres solas en Berlín es más alta ( $8 \%$ de todos los núcleos y casi la mitad de las familias con menores ${ }^{25}$ ), pero, en comparación con el resto de

24. El Welfare mix alemán se basa en una organización asistencial coordenada a nivel federal, de manera que garantiza la presencia de un servicio en cada zona y en torno a sectores especializados y grupos sociales específicos. A estos se suman, además, otras asociaciones locales de dimensiones inferiores.

25. Fuente: Mikrozensus 2004 (Statistisches Landesamt Berlin, 2005). 
Alemania, son familias menos numerosas ( 7 sobre 10 están compuestas por un solo hijo menor en comparación a 6 sobre 10 en Alemania) y menos jóvenes (poco más de 1 sobre 10 tiene menos de treinta años, la mitad de lo que se registra a nivel nacional (SGSV, 2002)). Las madres solas sufren déficit no tanto de escolaridad (SGSV, 2002), sino de formación ocupacional y de acceso al mercado de trabajo. El perfil típico de la madre sola en Berlín es el de una mujer ocupada con un rédito suficiente para mantener a la propia familia, pero la cuota de mujeres con problemas es muy relevante, sobre todo entre aquéllas con hijos pequeños: solo una de cada dos madres solas con niños menores de seis años trabaja (contra una media de cerca de $2 / 3$ ) y solo una minoría de éstas (43\%) obtiene un rédito suficiente para satisfacer las necesidades familiares (SGSV, 2002) a causa de la desigualdad de rédito que perjudica al mundo femenino y, principalmente, al recurso a empleos a tiempo parcial. El problema más evidente es la falta de servicios públicos para el cuidado de los hijos; el recurso a la política social es, en consecuencia, muy alto. Poco más del $10 \%$ recibe un subsidio de desempleo, mientras que cerca del $20 \%$ de las madres solas reciben un subsidio social y para el $14 \%$ de ellas se trata de la principal fuente de sustento. Si el hijo tiene menos de seis años, el porcentaje de madres «dependientes» de la Seguridad Social se dobla. Investigaciones recientes establecen la creciente crisis de las redes de apoyo familiar, sobre todo en forma de tiempo, es decir, en el cuidado de los hijos, mientras las transferencias provenientes del ex marido representan una fuente de ingresos de baja entidad y escasa certidumbre (SGSV, 2002).

Milán y Berlín, por tanto, se diferencian desde el punto de vista de las dinámicas demográficas y familiares: la capital alemana se sitúa plenamente en el modelo de sociedad urbana fragmentada (Mingione, 1991), caracterizada por la inestabilidad de las relaciones familiares y la fuerte presencia y expansión de las nuevas formas de familia; Milán, en cambio, se caracteriza por la limitada presencia — si bien va en aumento- de madres solas y por un modelo tradicional de familia en plena crisis.

\section{Metodología}

El análisis se basa en entrevistas retrospectivas realizadas en Milán y Berlín a familias con alto riesgo de pobreza y que reciben ayuda social. En Milán, se ha entrevistado a 17 madres ${ }^{26}$ residentes en vivienda de protección oficial; en Berlín, a 12 madres que reciben ayuda social del municipio ${ }^{27}$.

26. Los datos parten de un proyecto de investigación financiado por el Ministero dell'Istruzione, dell'Università e della Ricerca (MIUR) y del Comune di Milano y realizado por el Observatorio sobre la Pobreza Urbana del Departamento de Sociología e Investigación Social de la Università degli Studi di Milano Bicocca, coordinado por el profesor Enzo Mingione. La investigación sobre la vivienda social fue realizada en los primeros meses del año 2003 siguiendo el método CAPI.

27. Las entrevistas fueron recogidas por quien escribe estas líneas en el año 2005, durante un periodo de investigación realizado en la Humboldt Universität zu Berlin, en el marco de un programa europeo de movilidad de jóvenes investigadores (Research Training Network — RTN). 
Las entrevistadas en Milán son personas con problemas económicos, han sido seleccionadas ${ }^{28}$ por la Administración pública a través de procesos de comprobación de medios y reciben una ayuda que contribuye a mantenerlas fuera de la marginación social. Casi todas las entrevistadas en la capital alemana reciben algún tipo de subsidio. En Milán, los núcleos están compuestos en su mayor parte por la madre y dos hijos, a menudo ambos menores ${ }^{29}$. La persona de referencia tiene una edad relativamente alta (entorno a los cuarenta años), lo que coincide con el dato nacional (Zanatta, 2003). Son mujeres maduras que han pasado por la experiencia de la vida en pareja, habitualmente un matrimonio con hijos. La muestra de Berlín es más joven que la de Milán, pero también están presentes las mujeres maduras que suelen tener más de un hijo. En la muestra de Milán, el nivel educativo medio es bajo e inferior al de los entrevistados berlineses. La mayoría de las entrevistadas milanesas está ocupada, sobre todo en el sector terciario privado, mientras que en Berlín suelen estar sin trabajo, solo cinco de cada doce están ocupadas y casi exclusivamente se encuentran en el sector público.

El instrumento diacrónico utilizado en el análisis de los procesos de empobrecimiento permite seguir los periodos de pobreza experimentados en el pasado, lo cual amplía la capacidad explicativa. La perspectiva es interpretativa, dirigida a proponer elementos para comprender las dinámicas de empobrecimiento, con lo que se delinean tipologías según la metodología weberiana de los tipos ideales (Weber, 1958). La comparación entre núcleos efectivamente pobres y aquéllos que quedan fuera representa un recurso interpretativo importante para explicar qué eventos provocan empobrecimiento y qué recursos ayudan a evitarlo.

El estudio de cursos de vida se realiza con una metodología cuantitativa sobre datos longitudinales, aplicando una sequence analysis adaptada al bajo número de casos. Esta técnica analiza las carreras biográficas en su conjunto como secuencias complejas de eventos y condiciones (mobility pattern), más que dedicarse al estudio de los acontecimientos aislados (event history analysis) (Ruspini, 2002b). En particular, se intenta estudiar características de las familias (y su cambio en el tiempo), es decir, los motivos de su caída en la pobreza, los comportamientos frente al cambio y a las situaciones de dificultad. Según Andreß (1998), es posible analizar interpretativamente datos cuantitativos longitudinales, leyendo la secuencia de los acontecimientos para deducir líneas de conducta y estrategias ${ }^{30}$.

28. La escasa oferta de casas populares hace particularmente fuerte la selección operada por el sistema de bienestar: solo una minoría de las personas solas con hijos a cargo que lo solicitan obtiene una vivienda de protección oficial (poco menos del 30\% en el 1999) (Zajczyk, 2003).

29. En Italia, los padres solos tienen, la mayoría de ellos (tres núcleos de cada cuatro), un solo hijo menor (Zanatta, 2003). En esta muestra, la media es de 1,5.

30. Andreß sostiene que el uso de las técnicas estadísticas estándar es poco útil si se va más allá de las hipótesis y de los objetos de estudio más específicos (p. e.: los periodos de desocupación). En nuestro caso, se pretende, señalamos, analizar el desarrollo biográfico en su 
El análisis del curso de vida comprende cuatro fases. Para cada entrevista, se construyen tres secuencias diferentes, cada una de las cuales corresponde a una carrera biográfica relativa a la familia, al trabajo y a la vivienda. A éstas, se añade la secuencia relativa a las condiciones de pobreza (económica), distinta de la anterior porque se concentra en los episodios de pobreza económica, residencial, problemas físico-psicológicos (enfermedad e invalidez) y no sobre los eventos críticos como la precedente. Más allá de las cuatro secuencias descritas, tenemos a nuestra disposición informaciones «cualitativas» sobre los sucesos y sobre su rol en las biografías, pero también sobre los episodios de pobreza y las causas que los han determinado. De esta forma es, por tanto, posible distinguir los sucesos críticos de los positivos, transiciones que mejoran las condiciones de vida de otras que reducen los recursos disponibles.

La segunda fase prevé la construcción de relaciones entre secuencias, con el fin de analizar, por una parte, el vínculo causal entre sucesos y episodios de naturaleza diversa puestos sobre líneas secuenciales distintas, pero también desvelar estos mecanismos a través de la dimensión temporal.

La fase empírica sucesiva prevé la elaboración de una biografía «compleja» del individuo. Reducir a la unidad las diversas secuencias es coherente con la elección teórica de considerar la pobreza como multidimensional. Cada una de las dimensiones está representada por una secuencia biográfica y todas vienen recompuestas para delinear el proceso de empobrecimiento complejo y acumulativo.

El último paso del análisis empírico consiste en una sintesis tipológica de las trayectorias de empobrecimiento, utilizando esquemas comunes para cada ciudad y grupo social.

\section{Resultados}

\subsection{Empobrecimiento, las fases biográficas de riesgo}

El análisis de las dinámicas de caída en la pobreza parte de fases de vida y de episodios específicos que influyen sobre las condiciones existenciales de los entrevistados. Las diferencias culturales relativas al rol de la familia en los dos contextos deberían determinar diferencias en los tiempos y en los modos de esta transición. En realidad, la precocidad de la salida de casa de las entrevistadas

conjunto, y no sólo determinados elementos. El aspecto negativo de las técnicas cuantitativas es la dificultad (o imposibilidad) de incluir en el modelo de análisis y de controlar en su conjunto todos los cambios biográficos que intervienen en el núcleo familiar sobre los diversos ejes de desarrollo (familia, trabajo, bienestar, vivienda). En particular, el análisis de muchos eventos y estatus en los cuales los sujetos se encuentran en diversos momentos requiere un nivel de exactitud y precisión, que sólo procedimientos de «lectura» de las cadenas de datos (el caso individual a lo largo del tiempo) permiten. En esta investigación, además, la utilización de esta perspectiva es favorecida por la presencia de respuestas abiertas, en las cuales se indican además decisiones, acciones emprendidas, juicios subjetivos de los actores con relación a sucesos ocurridos y a las fases de vida experimentadas, los motivos de las dificultades y los instrumentos utilizados para afrontarla. 
parece un rasgo común a los dos contextos. Si, en el caso de Berlín, esto entra dentro de costumbres socioculturales, en Milán, en cambio, representa una excepción al «modelo de solidaridad parental», caracterizado por una larga cohabitación entre hijos adultos y padres (Mingione, 2005).

Más allá de este aspecto, sin embargo, se presentan muchas diferencias en las trayectorias de salida. La tendencia entre las entrevistadas berlinesas es salir de la familia para ir a vivir solas o convivir con alguien, lo que sigue un modelo de pareja cada vez más independiente del contrato matrimonial (SGSV, 2002). El modelo de pareja casada, característico de la sociedad industrial sobre el cual se han basado y están basados aún los sistemas de protección social, continúa prevaleciendo en Milán. La influencia de las dimensiones nacionales tiene, evidentemente, un rol importante: las tradiciones familiares, las características culturales de Italia y Alemania hacen distinguibles dos dinámicas diversas de salida de la familia de origen.

Un primer tipo de salida de la familia comporta más riesgos de exposición a la precariedad: una etapa de vida ya de por sí delicada deviene más arriesgada si la afronta una mujer sola, porque dispone de menos recursos económicos y relacionales. No estar casada representa una ulterior debilidad social también por cuestiones legales. La ley garantiza, al menos formalmente ${ }^{31}$, el sostén económico a la mujer por parte del marido. Las mujeres que pasan por el fin de una convivencia son, bajo este punto de vista, más vulnerables a las dificultades económicas y sociales.

Si se colocan las modalidades de salida del núcleo de proveniencia en escala decreciente de peligro de vulnerabilidad económica y social (solas, convivencia, matrimonio), las madres solas en Berlín muestran una mayor exposición al riesgo en la primera fase de vida independiente, en comparación con las madres solas en Milán.

Berlín y Milán se distinguen también por el rol desempeñado por las familias en esta fase delicada de la vida. En Milán, las entrevistadas han recibido, en la mayor parte de casos, un apoyo económico (sumas de dinero o ayuda para adquirir muebles para la casa nueva) en el periodo inmediatamente sucesivo a la salida de la familia de origen, mientras que en Berlín solamente unas pocas han disfrutado de esta protección.

No se notan, en cambio, diferencias relevantes entre los dos contextos por lo que respecta a los recursos residenciales a la salida de la familia de origen. En general, tanto en Milán como en Berlín, las mujeres recurren al alquiler. Mientras en Berlín ésta es la dinámica dominante vista la escasa proporción de vivienda en propiedad $^{32}$ y la relativa facilidad de encontrar casa, las madres

31. En el informe Armut und soziale Ungleichheit in Berlin (SGSV, 2002) y en la literatura italiana (Ruspini, 2002a; Zanatta, 2003), se sostiene que, a menudo, el marido no proporciona de hecho el apoyo económico previsto por la normativa.

32. Las viviendas ocupadas por propietarios representan una mínima parte de la totalidad (en 1993 , eran el $12,5 \%$ ) y la tendencia a vivir sobre todo en alquiler ha permanecido en vigor (Häußermann y Kapphan, 2004). 
solas milanesas reflejan la condición de las clases sociales bajas, que no pueden disfrutar de un recurso tan importante como es la casa en propiedad de la familia ${ }^{33}$. Las mujeres en ambas ciudades deben, por tanto, recurrir al mercado privado. Las milanesas encuentran, naturalmente, más dificultades por las características «excluyentes» del mercado, pero pueden recurrir a la ayuda económica de las familias de origen en medida muy superior a las entrevistadas de Berlín.

El modelo de salida de casa difiere entre las dos ciudades también en relación con la condición ocupacional de la mujer. En Milán, de hecho, la familia funciona objetivamente como incubadora de la formación y del ingreso en el mercado de trabajo: casi todas las entrevistadas salen tras haber iniciado una carrera laboral. Las pocas mujeres que no siguen este recorrido, es decir, que salen de casa, se convierten en madres y esposas y renuncian al trabajo, sufren mayores problemas una vez acabado el matrimonio. La trayectoria típica en Berlín es muy diferente: la joven sale de casa una vez terminada la propia formación pero antes de encontrar trabajo, en un contexto en el cual tener un empleo resulta más difícil que estabilizar la posición laboral.

La fase biográfica en la que tiene lugar la maternidad y el tipo de familia en la que se inserta la mujer son otro elemento interesante. Ni en Milán ni en Berlín el fenómeno de las madres adolescentes es particularmente común, como ocurre, en cambio, en otros contextos urbanos (Gran Bretaña y Estados Unidos). Entre nuestras entrevistadas, en efecto, la maternidad llega casi siempre en edades avanzadas, dentro de una condición familiar tradicional y, a menudo, de una situación laboral estable. En el caso berlinés, cuando la mujer no consigue encontrar trabajo o estabilizar su posición, puede apoyarse en los ingresos de su pareja.

En ambas ciudades, se confirma el modelo «clásico» de construcción de la familia — típico de la sociedad industrial— que prevé el nacimiento del primer hijo como etapa inmediatamente sucesiva al matrimonio o a la convivencia y que se debe basar en el rol materno (exclusivo y prevalente) de la mujer, por el cual resulta difícil conciliar deberes laborales y familiares. Este modelo, más allá de las reflexiones sobre la desigualdad de género en el interior del hogar, resulta, la mayoría de las veces, protector para todo el núcleo. La división del trabajo y el intercambio de recursos internos en la familia son beneficiosos para todos: la mujer es la proveedora de atención a todos los miembros de la casa, el hombre distribuye el rédito del trabajo, la eventual escasez de rédito podrá ser afrontada mediante los recursos provenientes de una medida social, sobre todo en Berlín, a través de los subsidios de desocupación o el subsidio social, o el sostenimiento de las redes de relaciones en Milán.

La ruptura de las parejas hace, en cambio, emerger con fuerza el riesgo para la mujer típico de este modelo, en particular cuando la mujer tiene dificulta-

33. Se trata de una característica típica italiana que es también consecuencia de las políticas de vivienda, que han empujado a la propiedad de la vivienda, en parte también en el caso de las clases sociales medio-bajas (Tosi, 1984 y 2005). 
des para entrar (o reentrar) en el mercado de trabajo tras la fase más crítica del cuidado de los hijos, principalmente tras la separación.

Un ulterior rol negativo del matrimonio emerge en Berlín: las difíciles relaciones con la pareja o el marido — volveremos a ello en el próximo parágrafo- son determinantes para la condición económica y social de la mujer.

\subsection{Los procesos de empobrecimiento}

Después de haber afrontado las fases críticas de transición a la vida adulta, pasamos a considerar las trayectorias de empobrecimiento. En las muestras de madres solteras, la experiencia de pobreza económica es muy frecuente, de manera que, si se consideran episodios presentes y pasados, pocas entrevistadas en las dos ciudades han permanecido fuera de procesos de carencia.

En Milán, más que en Berlín, la condición de pobreza en el momento de realizar la entrevista se asocia a los periodos de dificultad precedente: casi todas las madres solas bajo la línea de pobreza han experimentado episodios de carencia en el pasado o viven una condición de precariedad persistente que se transforma en periodos de pobreza en coincidencia con eventos críticos. Entre las madres solas milanesas, los episodios de pobreza duran aproximadamente un año ${ }^{34}$. Los periodos de pobreza de las madres solas berlinesas tienen una duración superior $y$, por consiguiente, efectos debilitadores más graves.

El empleo se muestra como la mejor solución y la más frecuente entre las entrevistadas de ambas ciudades: donde el empleo es más accesible (Milán), los episodios de pobreza son más breves respecto al contexto en el cual la ocupación es escasa y el problema para las mujeres con hijos es el acceso a un puesto de trabajo más que el peligro de perderlo (Berlín). El modelo de Milán constituye un modelo de pobreza recurrente, caracterizado por episodios de carencia económica ${ }^{35}$ sucesivos experimentados en pocos años. El de Berlín, en cambio, es de pobreza prolongada, caracterizada por pocos episodios de larga duración.

Los periodos de pobreza se producen casi exclusivamente cuando la mujer es madre sola: la transición a dicho estatus implica un empeoramiento de sus condiciones de vida respecto al periodo en pareja o bien respecto a la familia de origen. La maternidad y el cuidado de los hijos comportan un aumento de las exigencias de tiempo y de recursos económicos que la familia tradicional consigue más fácilmente sostener con el doble rédito y la división desigual de los roles sociales. Las mismas condiciones representan un riesgo de pobreza elevado también en el interior de la familia tradicional (y a doble rédito), y se convierten en difícilmente soportables para la madre sola. La causa de la pobre-

34. Los episodios de duración media pueden haber incidido también sobre las condiciones actuales de la familia, si debilitan las capacidades de los sujetos. La escasez de rédito puede, de hecho, asociarse a la producción de ulteriores problemas desde el punto de vista psicológico, motivacional, de salud, etc. (Sen, 2000).

35. Al episodio de pobreza pasado (que se verifica en 10 casos de cada 17), se añade el actual. Se observa, por tanto, una tendencia a repetirse los episodios de pobreza. 
za y de la permanencia en esta condición es la insuficiencia de una sola fuente de rédito y de cuidado frente a exigencias múltiples por la presencia de hijos menores ${ }^{36}$.

El proceso de empobrecimiento tiene inicio, habitualmente, mediante la transición de pareja casada con hijos pequeños a madre sola. El evento mismo de la separación o del luto, la disminución drástica del rédito familiar y la consiguiente dificultad en la conciliación de los roles de madre y trabajadora representan el inicio de las dificultades. En ambas ciudades, éste es el acontecimiento que causa más a menudo la carencia, sea directamente, sea indirectamente, porque representa el paso biográfico que debilita dramáticamente el capital de recursos a disposición de la mujer.

La falta de trabajo y el bajo salario son indicados como determinantes para la pobreza, tanto en Milán como en Berlín. En la primera ciudad, la pobreza económica de las madres solas está vinculada no a la desocupación, como en el caso berlinés, sino a la dificultad de conciliar trabajo y deberes de cuidado. En Milán, la desocupación representa un problema solo en un par de casos y, habitualmente, por breves periodos. Las mujeres que, tras etapas de inactividad o de desocupación durante el matrimonio, deben encontrar trabajo, como consecuencia del fin de la vida de pareja, consiguen insertarse en poco tiempo en el mercado de trabajo.

La mujer que deja el trabajo o que no consigue insertarse en el mercado laboral resiente limitadamente esta condición en el periodo en el que vive en pareja, y su rol, reproducido por la cultura y por las instituciones del contexto, se ve centrado en el cuidado de la familia y, solo en segunda instancia, en el sostén económico del núcleo. Los efectos de la inactividad laboral son casi siempre indirectos y a medio término: un periodo de desocupación "protegido» por la familia tradicional condiciona negativamente las posibilidades de inserción laboral que siguen al fin del matrimonio y limita el nivel retributivo.

La estabilidad ocupacional constituye, en cambio, un factor decisivo para evitar caer en procesos de empobrecimiento. Es decir, las entrevistadas que, en Milán, encuentran un puesto de trabajo estable antes de casarse o durante el matrimonio no experimentan los efectos negativos de la separación o del periodo posterior. La inestabilidad laboral, como secuencia de empleos en el periodo de monoparentalidad y como alternancia entre desocupación y periodos de trabajo en la fase de pareja, actúa negativamente sobre los niveles de rédito y sobre las capacidades de ahorro. En otros casos, sí tienen trayectorias de estabilización de la condición ocupacional, que puede revelarse, sin embargo, como insuficiente en presencia de eventos críticos — por ejemplo: la enfermedad propia o la de un hijo- si las madres solas no encuentran una ayuda válida en la red de solidaridad familiar ni en el subsidio social.

36. La adecuación del rédito depende estrechamente de las exigencias que debe satisfacer. Por este motivo, se usan escalas de equivalencia, que ponderan el rédito familiar indispensable para una vida digna, y se recoge también el juicio subjetivo de los entrevistados, que ponen directamente en relación necesidades y capacidades de satisfacerlas en las diversas fases de su vida. 
En Milán, las entrevistadas muestran una precariedad económica estable en el tiempo, que es efecto de la desigualdad social estructural. Los eventos críticos, la imposibilidad de activar recursos para reaccionar a éstos, el fallo de la capacidad de compensación entre esferas redistributivas de lo social (familia, trabajo y Estado) determinan el salto de la desigualdad a la pobreza como condición «normal» de la sociedad capitalista avanzada.

En Berlín, por el contrario, a los problemas de conciliación se añade la desocupación, que, en esta ciudad, golpea con fuerza a las madres solas, también por su baja calificación profesional. El sistema de asistencia es tan generoso que limita el vínculo entre desocupación y pobreza, pero es menos eficaz cuando la primera se vuelve crónica (desocupación de largo y muy largo plazo) ${ }^{37}$. El problema laboral se presenta para las mujeres jóvenes (de veinte a treinta años) como dificultad de acceso al mercado de trabajo, de estabilización de las primeras experiencias laborales vinculadas al sistema formativo (el Dual System alemán). Para las mujeres maduras, sin embargo, la desocupación es la consecuencia de la exclusión de medio-largo periodo, tras el ingreso en el mercado de trabajo en las décadas de 1970 y 1980, cuando las condiciones económicas generales y laborales eran mejores en ambas partes de la ciudad, que entonces estaba dividida. Desde el punto de vista de las perspectivas de inserción laboral, ambos perfiles experimentan grandes dificultades, a causa, respectivamente, de la falta o de la obsolescencia de competencias profesionales.

Por tanto, en la ciudad rica - Milán-, las desigualdades producen madres solas working poor, una forma típica del modelo de la nueva pobreza urbana. El recurso al mercado de trabajo, por dinámico que sea, puede no ser suficiente para impedir procesos de pauperización: las entrevistadas tienen ocupaciones con bajo salario, insuficientes para garantizar un mínimo de bienestar de núcleos familiares aprisionados entre necesidades sociales muy altas y un contexto urbano muy costoso. En Berlín, ciudad empobrecida, por el contrario, la pobreza golpea a mujeres excluidas del mercado de trabajo, que, aún asistidas por los servicios sociales, no son capaces de satisfacer las necesidades propias ni las de los hijos menores.

Incluso si los perfiles de la pobreza son muy diferentes entre Milán y Berlín, es similar el rol de los recursos relacionales como factor de disminución del riesgo. El apoyo de familiares y amigos es decisivo en un contexto urbano rico y costoso como Milán (Zanatta, 2003), en el cual las familias con menores están polarizadas entre núcleos con dos réditos, que tienen niveles de vida y redes de apoyo elevados, y aquéllos como las madres solas, caracterizados por un único y bajo rédito, que, sin apoyo familiar, tienden a la exclusión y a la transmisión intergeneracional de la pobreza (Mingione, 2005). También en Berlín los recursos relacionales tienen un rol importante en los momentos en los que tanto la economía como el Estado fallan (SGSV, 2002), puesto que impiden que la precariedad se transforme en pobreza o que ésta última se con-

37. El subsidio social, de importe inferior, sustituye al de desocupación. 
vierta en crónica. Entre las entrevistadas en Milán y Berlín, pueden recibir ayuda, respectivamente, la mitad y un tercio de las madres solas, pero la cuota se divide a la mitad entre aquéllas que se encuentran bajo el umbral de la pobreza. En los dos contextos, la posibilidad de recurrir a la ayuda de familiares y amigos discrimina entre las entrevistadas: quien ha gozado de este sostén, ha conseguido salir de los periodos de pobreza y mantenerse libre de carencias.

Como hemos anticipado, un elemento distintivo entre las causas de empobrecimiento en Berlín es el rol negativo del matrimonio y la convivencia en los procesos de empobrecimiento. Más a menudo en la capital alemana que en Milán, la familia tradicional puede ser la causa directa de las dificultades económicas y de los problemas por las difíciles relaciones entre la pareja y la gestión desigual de los recursos internos del núcleo del hogar.

Es justamente en este ámbito que emerge, entre las entrevistadas en Berlín, el endeudamiento como modalidad de empobrecimiento típica del contexto que, en el caso de las entrevistadas, sucede siempre en el interior de la pareja. Es consecuencia de la escasa capacidad de gestión del dinero por parte de la pareja en perjuicio de la mujer, que sufre de forma aún más dramática la desigual gestión de los recursos económicos familiares. El endeudamiento es lento y progresivo, reconocido demasiado tarde, porque aviene no en relación con un acontecimiento en particular (un gasto imprevisto y necesario por graves motivos), sino que, al contrario, surge por adquisición (a crédito) de bienes de consumo de masa.

El análisis de las dinámicas de carencia confirma la hipótesis de que los procesos de empobrecimiento de las madres solas son causados por efectos simples ${ }^{38}$, emanados de un solo evento crítico que empeora una situación ya de por sí difícil.

\subsection{Las carreras residenciales}

Aún habiendo evidentes diferencias entre las dos ciudades y los respectivos mercados inmobiliarios, la condición residencial de las madres solas es crítica en ambas ciudades, como pone de manifiesto la sobrerrepresentación de este grupo en la vivienda pública, tanto en Milán como en Berlín (Zajczyk, 2003; SGSV, 2002).

El análisis de las trayectorias residenciales ${ }^{39}$ enriquece el estudio de trayectorias de empobrecimiento con la movilidad residencial. Se toman en consideración no solo el número de mudanzas, sino también los motivos de los cambios y el tipo de situación. Esto permite, por una parte, distinguir entre casos de transferencia crítica (cambios no programados, consecuencias de even-

38. La definición de efecto simple se ha explicado en la nota 12.

39. Las dos muestras tienen características distintas por el tipo de vivienda y las medidas de asistencia residencial. Las entrevistadas milanesas son orgánicamente asistidas por el sistema público, en tanto han tenido acceso a la vivienda social. Las de Berlín viven en residencias en alquiler, pero en algunos casos reciben subsidios y cambian a la vivienda social. 
tos negativos y, por tanto, dificultades) y voluntarios debidos a mejorías de las condiciones de vida y/o laborales (matrimonio, nacimiento de los hijos, acceso al trabajo, compra de la casa) y, por otra, valorar los pasajes tras los diversos tipos de residencia (de la vivienda de propiedad a aquélla de alquiler privado, a la vivienda popular, hasta la condición de uso gratuito o de hospitalidad).

La carrera residencial en Milán resulta bastante estable, puesto que se caracteriza por pocos cambios de una vivienda a otra. Las madres solas milanesas entran, además, en un modelo de exclusión del mercado residencial de medio periodo, caracterizado por una primera fase de inclusión en el mercado residencial privado y una relativa estabilidad ocupacional y residencial, que desaparecen con el fin del matrimonio. La inclusión es efecto de la condición de pareja y se revela para las mujeres solo aparentemente estables: una vez agotadas las ayudas familiares para el primer cambio y acabado el matrimonio, la mujer se reencuentra con problemas al relacionarse con un mercado residencial costoso. Solo una minoría de las entrevistadas accede a la vivienda social a través de una convocatoria o a un subalquiler, lo que indica una condición de carencia precedente a la separación. La mayor parte de las entrevistadas obtiene la vivienda mediante procedimiento de urgencia de la Administración local tras la separación o, en un caso, ocupando abusivamente el apartamento.

Algunos elementos que emergen de este análisis dinámico — la estabilidad residencial de la pareja, las inmediatas dificultades de las madres solas salidas del matrimonio, las dinámicas negativas de las familias que experimentan acontecimientos críticos- dan la idea de un mercado residencial rígido y selectivo. Rígido porque el recurso residencial es generalmente escaso para los réditos medio-bajos; excluyente porque, quien entra en trayectorias de depauperización, está expuesto a fuertes riesgos de sufrir problemas residenciales o expulsión de la ciudad por falta de sostén por parte de las redes de relaciones o de la asistencia social. Las madres solas que hemos entrevistado representan aquella minoría de núcleos de bajo rédito que la ayuda pública ha mantenido en la ciudad y fuera de mecanismos de pobreza grave o prolongada.

La situación residencial en Berlín es más favorable, en particular, por la mayor oferta de casas, que mantiene los precios relativamente bajos. Las carreras residenciales son muy dinámicas (numerosas transferencias en relación con los años de vida independiente), lo que confirma la hipótesis de la movilidad residencial como recurso: el actor puede escoger una vivienda adecuada a las propias posibilidades económicas, a las exigencias de espacio y a las preferencias sobre el barrio donde quiere vivir. Se manifiesta una relativa libertad de movilidad residencial que permite encontrar soluciones que se adaptan al cambio de las condiciones económicas y familiares: trayectorias hacia arriba, a la mejora de las condiciones residenciales, incluso a la posibilidad de escoger en qué barrio se vive, $y$, por otra parte, trayectorias hacia abajo, que solo en algunos casos pueden desembocar en problemas residenciales, aunque, sin embargo, se pueden encontrar soluciones en los recursos relacionales y en la asistencia social.

Encontramos dos factores que alimentan y sostienen este fenómeno. Por una parte, las relaciones sociales que proporcionan canales informativos: a 
menudo, son los conocidos quienes indican soluciones residenciales adecuadas a las propias exigencias. Por otra, la intervención del sistema de asistencia social en caso de problemas residenciales contribuye a impedir posibles dificultades para encontrar o mantener una vivienda, puesto que concede subsidios para sostener los gastos de alquiler o de gestión de la casa.

El elemento decisivo en Berlín no es solo la entidad del subsidio, sino también los tiempos relativamente reducidos de la asignación. En el caso de Milán, por el contrario, el acceso a la casa popular, que es la medida de intervención prevalente y más eficaz, tiene tiempos mucho más largos y es extremadamente selectivo. Esto comporta que las dificultades residenciales se alarguen, con la excepción para los sujetos que tienen acceso a las viviendas sociales mediante procedimientos de urgencia, como nuestras entrevistadas.

\subsection{Modelos de empobrecimiento}

La estrategia para la construcción de modelos de empobrecimiento consiste en verificar como la capacidad de reacción a dificultades económicas y a cambios se debilita a lo largo del tiempo. La pérdida de la facultad de hacer frente a las dificultades puede ser efectivamente descrita como pobreza, no en sentido económico, sino en sentido más amplio, como pérdida de capacitación (Sen, 2000), proceso debido al progresivo o repentino derrumbe del conjunto de recursos que cada actor tiene a su disposición. Los elementos tenidos en consideración son, por una parte, las características sociales adscritas y, por otra, los eventos y los episodios que, a través de la biografía personal y familiar, debilitan los mismos recursos hasta provocar trayectorias de empobrecimiento.

Han sido construidas tres trayectorias de empobrecimiento y los tipos ideales de «víctima»:

- Empobrecimiento de género: víctimas del rol social femenino interno en la familia tradicional.

- Empobrecimiento por transformaciones económicas: víctimas de factores estructurales.

— Empobrecimiento por elecciones biográficas «peligrosas»: víctimas de agencia.

En el primer tipo de trayectoria ideal típica entran las madres solas víctimas de la estructura familiar tradicional, central en las sociedades industriales $y$, a menudo, punto de referencia de los sistemas de asistencia social en la sociedad postindustrial. La mujer representa la única fuente de cuidados, y esta dedicación (a menudo no solo con los hijos, sino también con los padres o los hermanos) se revela como una limitación a la realización de objetivos individuales, en particular laborales, y, por tanto, a la posibilidad de ser (al menos en parte) autónoma de la pareja. Este tipo de trayectoria se produce cuando la mujer sufre, por una parte, la desigualdad de roles interna a la familia y, por otra, los efectos negativos de un sistema urbano rígido (en la relación entre 
mercado de trabajo, servicios de atención, sistema de asistencia social) respecto a los cambios sociales en la institución familiar. Es esta la trayectoria típica de gran parte de las madres solas en Milán. De la familia de origen, la mujer sale para casarse tras la inserción en el mercado laboral; la mujer trabajadora se convierte en madre y ello comporta el abandono del trabajo y las dificultades económicas sucesivas a la separación. En Berlín, esta trayectoria es diferente, porque la mujer entra o busca entrar en el mercado laboral tras haber formado una nueva familia, lo que retarda ulteriormente y hace más difícil la búsqueda de un puesto de trabajo.

De las entrevistas en Berlín, emerge también la segunda modalidad del modelo de empobrecimiento de género, en la cual entran las mujeres que han vivido experiencias relacionales negativas durante el matrimonio. La relación con la pareja, caracterizada por la violencia o por la incorrecta gestión económica, provoca un empeoramiento rápido de los recursos familiares y de aquéllos con los que la mujer se encontrará después para gestionar en la fase sucesiva a estas relaciones de breve duración.

En ambas modalidades, el proceso de empobrecimiento sucede en un periodo de tiempo prolongado a una edad madura. Tras años vividos en condiciones de recursos limitados sin pobreza, se verifica un empeoramiento de las condiciones de vida.

La segunda trayectoria ideal típica concierne a mujeres con experiencias laborales largas y estables, que, frente al cierre de una empresa o a la pérdida del puesto de trabajo a causa de una edad avanzada y de competencias profesionales obsoletas, tienen dificultades para insertarse en el mundo laboral. Esta trayectoria está estrechamente vinculada a los cambios del mercado de trabajo y solo aparentemente depende menos de las vicisitudes biográfico-familiares. La inestabilidad laboral (Milán) o la exclusión laboral (Berlín) se agravan por la combinación entre deberes de cuidado de los hijos y problemas de acceso al empleo de las mujeres de bajo nivel sociocultural.

Las trayectorias de empobrecimiento son la manifestación microsocial del cambio estructural del sistema de producción y de los efectos de éste en términos de desocupación y de dificultad de reinserción laboral. La diferencia entre las dos ciudades está en la duración de los periodos de dificultad laboral. Para valorar las consecuencias sobre los sujetos, se tiene en cuenta el contexto, las condiciones del mercado laboral y de la asistencia social. En Milán, un periodo breve de desocupación resulta más grave por la escasez de subsidios. Si es verdad que es más fácil encontrar trabajo, es verdad también que un episodio de desempleo breve puede ejercer efectos negativos sobre las mujeres que no tienen buenas redes de relación que las apoyen. En Berlín, las entrevistadas sufren periodos más largos de desocupación, durante los cuales, sin embargo, los subsidios proporcionan sostén económico. Se trata, de hecho, de mujeres que, a diferencia de las más jóvenes, tienen acceso a medidas de asistencia más generosas (pensadas para el breadwinner). En Milán, en cambio, los episodios de desempleo son más breves, pero se repiten en el tiempo y tienen también efectos negativos, vistos la edad de estas mujeres, el riesgo de que- 
dar excluidas de la estabilidad laboral y las necesidades económicas relativas al cuidado de los hijos.

En tercer lugar, están las trayectorias de empobrecimiento de las mujeres que, teniendo pocos recursos, caen en dificultades, por elecciones de vida arriesgadas (agencia) que las hacen más vulnerables a los eventos críticos. Es un perfil más frecuente entre las entrevistadas en Berlín, que tiene, sin embargo, un elemento generacional común: han nacido en los años cincuenta y se independizaron en los años setenta: el particular clima cultural de esa década las podría haber empujándo a comportamientos "de riesgo" que buscasen la construcción de la independencia a través de trayectorias biográficas y familiares no usuales ${ }^{40} \mathrm{y}$, por tanto, poco protegidas por los sistemas de regulación social.

\section{Conclusiones}

El cuadro que emerge del análisis de los cursos de vida y de los procesos de empobrecimiento de las madres solas de Milán y Berlín muestra notables diferencias entre los dos contextos.

Las madres solas entrevistadas en Berlín están afectadas por varias formas de inestabilidad biográfica y laboral, que hacen efectivamente precarios los cursos de vida. La rápida crisis de los proyectos matrimoniales, la extrema dificultad para pasar de las primeras experiencias laborales a una ocupación estable, la fuerte autonomía de la familia de origen, la cual a menudo se rechaza o de la cual no se desea pedir ayuda, estructuran una completa precariedad biográfica. Ciertamente, el recurso a la asistencia social ayuda a prevenir o a limitar los periodos de pobreza, pero sigue siendo importante la inestabilidad de los cursos de vida, que parece remitirnos a las representaciones de la sociedad postindustrial teorizadas en los últimos decenios (Beck, 2003; Mayer, 2003). En este sentido, las madres solas de Berlín parecen confirmar la presencia de este fenómeno de individualización de los cursos de vida, que acaba por ser una fuente de riesgo constante en la vida de estos sujetos.

Las madres solas de Milán, en cambio, aún encontrándose en dificultades económicas, tienen cursos de vida estables. Esta diferencia está producida en especial por el rol de apoyo de la familia y por la inclusión en el mercado de trabajo.

Resulta, por ello, imposible confirmar la hipótesis inicial de una convergencia entre contextos urbanos basada sobre la precarización común de algunos sectores sociales. Emerge, en cambio, la importancia de factores contextuales en determinar trayectorias biográficas individualizadas. La interrelación entre condiciones estructurales, factores culturales, fases de vida y elementos biográficos parece determinar la presencia o la ausencia de elementos de precarización.

40. Algunos ejemplos recogidos en las entrevistas son los siguientes: maternidades fuera de la pareja, salida del mercado de trabajo a edad madura para completar estudios sin una fuente de rédito alternativa, preferencia por trabajos satisfactorios pero poco retribuidos respecto a carreras laborales seguras. 
Parece creíble que la precarización esté vinculada con una fase de la vida más que con un grupo social caracterizado por recursos escasos.

La teoría de los ciclos de vida de Rowntree (2000) requiere, sin embargo, una observación adicional: el fin del matrimonio y, como consecuencia, la monoparentalidad, amplifican el riesgo de pobreza típico de las mujeres con perfiles socioeconómicos débiles, que se encuentran en una fase de vida crítica, en la cual tienen hijos y carreras que están aún iniciando y a menudo son inestables. La pobreza femenina resulta ser, al menos en el caso de las madres solas, un efecto combinado entre una fase de vida tradicionalmente crítica, como la maternidad y el cuidado de los hijos pequeños, y la desestructuración, ésta típicamente contemporánea, de las formas tradicionales de familia. Las mujeres pertenecientes a las clases sociales más débiles, que atraviesan esta fase proviniendo de estructuras familiares tradicionales, afrontan una situación de debilidad que puede transformarse fácilmente en pobreza.

Los procesos de empobrecimiento de las entrevistadas tienden a divergir entre modelos dinámicos locales. Por una parte, encontramos la pobreza recurrente de las madres solas de Milán y, por otra, la pobreza prolongada de las mujeres de Berlín.

Entre las madres solas milanesas, prevalece aquello que hemos definido como empobrecimiento de género, que sigue a un periodo de vida más o menos largo de estabilidad en el cual actúan las desigualdades de género, si bien en modo latente. En Berlín, en cambio, la llegada de problemas económicos y sociales acaece a través de trayectorias más diversas (aparecen en modos uniformes los tres modelos de empobrecimiento), pero principalmente como recaída de formas de inestabilidad biográfica ya radicadas, del punto de vista laboral y familiar, que, al presentarse un evento crítico, empujan a la mujer a la pobreza.

A estos patterns distintos corresponden también perfiles sociales bien determinados, como aquéllos del working poor de la ciudad rica y el de las madres solas excluidas del mercado de trabajo en la ciudad en crisis.

\section{Referencias bibliográficas}

AlCOCK, P. (2003). «L'influenza delle prospettive dinamiche sull'analisi della povertà e sulle politiche contro la povertà in Gran Bretagna». En: ALCOCK, P. y SizA, R. La povertà oscillante. Sociologia e Politiche Sociali, vol. 6-2. Milán: FrancoAngeli.

ANDREß, H.J. (1998). Empirical poverty research in a comparative perspective. Aldershot: Ashgate, England.

BagnaSCO, A. y Negri, N. (1994). Classi, ceti, persone: Esercizio di analisi sociale localizzata. Nápoles: Liguori.

BECK, U. (2003). La società del rischio: verso una seconda modernità. 2a ed. Roma: Carocci. Edición original: Risikogesellschaft. Frankfurt an Main: Suhrkamp Verlag, 1986.

BENASSI, D. (2002). Tra benessere e povertà. Sistemi di Welfare e traiettorie di impoverimento a Milano e Napoli. Milán: FrancoAngeli.

- (2005). La povertà come condizione e come percezione. Una survey a Milano. Milán: FrancoAngeli. 
BenASSI, D. y MingIONE, E. (2004). «La povertà in un contesto ricco: i milanesi che rimangono poveri». En: Negri, N. y SARACENO, C. Povertà e vulnerabilità sociale in aree sviluppate. Roma: Carocci.

BonNy, Y. y BosCO, N. (2004). «Misure di sostegno al reddito per i poveri in alcune città europee». En: SARACENO, C. (2004). Le dinamiche assistenziali in Europa. Bolonia: Il Mulino. Edición original: Social assistance dynamics in Europe: National and local poverty regimes. Bristol: Policy Press, 2002.

BоОтH, C. (1903). Life and labour of the people of London. 17 vols. Londres: Routledge.

CASPER, L. y MCLANAHAN y GARFINKEL, I. (1994). "The gender-poverty gap: What we can learn from other countries». American Sociological Review, 59 (4), 594-605.

CavalcA, G. y ZajCZYK, F. (2006). "Povertà al femminile in un contesto ricco: la donna a Milano tra instabilità occupazionale, abitativa e familiare». En: MAZZETTE, A. L’urbanità delle donne: Creare, faticare, governare ed altro. Milán: FrancoAngeli.

DALY, M. (1992). "Europe's poor women? Gender in research on poverty». European Sociological Review, 8 (1), 1-12. Oxford. Nueva York: Oxford University Press.

Dorsch, P.; Häubermann, H.; Kapphan, A.; Keim, R.; Kronauer, M.; Schumann, C.; SieBerT, I. y VogeL, B. (2000). Comparative statistical analysis at national, metropolitan, local and neighbourhood level. Germany: Berlin and Hamburg. Amsterdam: Amsterdam Study Centre for the Metropolitan Area (AME). URBEX Series, 4.

Engels, F. (1845). Die Lage der arbeitenden Klasse in England. Leipzig: Verlag Otto Wigand.

ESPING-ANDERSEN, G. (1990). The three worlds of welfare capitalism. Cambridge: Polity Press.

FERRERA, M. (1996). "The southern model of welfare in social Europe». Journal of European Social Policy, 1, 17-37.

- (2005). The boundaries of welfare. European integration and the new spatial politics of social protection. Oxford y Nueva York: Oxford University Press.

Gallie, D. y Paugam, S. (2000). "The experience of unemployment in Europe: The debate». En: Gallie, D. y PAUGAM, S. (ed.). Welfare regimes and experience of unemployment in Europe. Nueva York: Oxford University Press.

GidDENS, A. (1990). La costruzione della società. Milán: Edizioni di Comunità. Edición original: The constitution of society. Cambridge: Polity Press, 1984.

HäUßERMANN, H. y KaPPHAN, A. (2004). «Berlin: from a divided into fragmented city». The Greek Review of Social Research, 113, 25-61. Atenas: National Centre of Social Research Greek.

HÄUßERMANN, H. y KaZEPOV, Y. (1999). «Urban poverty in Germany: A comparative analysis of the profile of the poor in Stuttgart and Berlin». En: MinGIONE, E. (1999). Urban poverty and the underclass. Oxford: Blackwell.

Kapphan, A. (2002). Das Arme Berlin. Sozialräumliche Polarisierung, Armutskonzentration und Ausgrenzung in den 1990er Jahren. Opladen: Leske +Budrich.

LAWSON, R. (1995). "The challenge of "new poverty": Lessons from Europe and North America». En: FUNKEN y COOPER (ed.). Old and new poverty: The challenge for reform. Londres: Rivers Oram Press.

LEISERING, L. (2003). «I due usi delle ricerche dinamiche sulla povertà. Modelli deterministici e contingenti delle carriere individuali di povertà». En: ALCOCK, P. y SizA, R. La povertà oscillante. Sociologia e Politiche Sociali, 6-2. Milán: FrancoAngeli.

LEISERING, L. y LEIBFRIED, S. (1999). Time and poverty in western welfare states. United Germany in perspective. Cambridge: Cambridge University Press. 
MAYER, K.U. (1987). «Lebenslaufforschung». En: VOGES. Methoden der Biographieund Lebenslaufforschung. Opladen: Leske+Budrich.

- (2003). "New ways of life or old rigidities?: Changes in social structures and life courses and their political impacts». Working Paper Political Economy and Life Course in Advanced Societies (POLIS). Max Plank Institute Berlin.

Mingione, E. (1991). Fragmented societies: A Sociology of economic life beyond the market paradigm. Oxford: Blackwell.

- (1997). Sociologia della vita economica. Roma: Carocci.

- (1999). Urban poverty and the underclass. Oxford: Blackwell.

- (2000). "Prefazione». En: RusPinI, E. L'altra metà della povertà: Uno studio sull'impoverimento femminile in Germania e in Gran Bretagna. Roma: Carocci.

- (2001). «Il lato oscuro del welfare: trasformazione delle biografie, strategie familiari e sistemi di garanzia». En: Tecnologia e società, Atti dei Convegni Lincei n. 172. Roma: Accademia Nazionale dei Lincei, 147-169.

- (2005). «Verso un'interpretazione della povertà a Milano». En: BENASSI, D. (2005). La povertà come condizione e come percezione: Una survey a Milano. Milán: FrancoAngeli.

Negri, N. (1990). Povertà in Europa e trasformazione dello stato sociale. Milán: FrancoAngeli.

Rowntree, B. (2000). Poverty. A study of town life. The Policy Press. Edición original: Londres: McMillan, 1901.

RUSPINI, E. (2000). L'altra metà della povertà: Uno studio sull'impoverimento femminile in Germania e in Gran Bretagna. Roma: Carocci.

- (2002a). "Tra visibilità e invisibilità: le madri sole in Italia». En: TrIVELLATO, P. Giovani madri sole: Percorsi formativi e politiche di welfare per l'autonomia. Roma: Carocci (ed.).

- (2002b). Introduction to longitudinal research. Londres: Routledge.

SARACENO, C. (2004). Le dinamiche assistenziali in Europa. Bolonia: Il Mulino. Edición original: Social assistance dynamics in Europe: National and local poverty regimes. Bristol: Policy Press, 2002.

SASSEN, S. (1999). "Service employment regimes and new inequality». En: MingIONE, E. (1999). Urban poverty and the underclass. Oxford: Blackwell.

- (2001). The global city: New York, London, Tokyo. 2a ed. Princeton, N.J: Princeton University Press.

SchizZerotTo, A. (2002). Vite ineguali: Disuguaglianze e corsi di vita nell'Italia contemporanea. Bolonia: Il Mulino.

Sen, A. (2000). Lo sviluppo è libertà: Perché non c’è crescita senza democrazia. Milán: Mondadori. Edición original: Development as freedom. Nueva York: Knopf Press, 1999.

SGSV (SENATSVERWALTUNG FÜr Gesundheit, SOZIALES und VerbraUCHERSCHUTZ) (2002). Armut und soziale Ungleichheit in Berlin.

Simmel, G. (1989). «Il povero». En: Sociologia. Milán: Edizioni di Comunità. Edición original: Soziologie: Untersuchungen über die Formen der Vergesellschaftung, Berlín: Bunker \& Humblot, 1908.

SiZA, R. (2003). «Povertà stabili e povertà temporanee: tra precarietà diffusa e processi di esclusione». En: AlCOCK, P. y SizA, R. La povertà oscillante. Sociologia e Politiche Sociali, 6-2. Milán: FrancoAngeli.

SLB (StaTistisches LANDESAMT Berlin) (2005). Berliner Statistik: Datenangebot aus dem Mikrozensus im März 2004. 
Tosi, A. (1984). «La politica della casa». En: Ascoli, U. (ed.). Welfare state allitaliana. Bari: Laterza.

- (2005). Case, quartieri, abitanti, politiche. Milán: Liberia Clup.

Townsend, P. (1979). Poverty in United Kingdom. Harmondsworth: Penguin Book.

WeBER, M. (1958). «Alcune categorie della sociologia comprendente». En: Il metodo delle scienze storico-sociali. Turín: Einaudi. Edición original: «Über einige Kategorien der verstehenden Soziologie». En: Gesammelte Aufsätze zur Wissenschaftslehre. Tübingen: Mohr, 1922.

ZanatTA, A. L. (2003). Le nuove famiglie. Bolonia: Il Mulino.

ZAJCZYK, F. (2003). La povertà a Milano: Distribuzione territoriale, servizi sociali e problemi abitativi. Milán: FrancoAngeli.

- (2005). «Segregazione spaziale e condizione abitativa». En: BENASSI, D. (2005). La povertà come condizione e come percezione: Una survey a Milano. Milán: FrancoAngeli. 